\title{
Getting into Learners' Pace: QR-Coded Supplemental Materials for SHS Learners in the Division of Laguna, Philippines
}

\author{
Elymar A. Pascual \\ elymarpascual@rocketmail.com \\ Department of Education, Nagcarlan, Laguna, Philippines, 4002
}

\begin{abstract}
"QR" stands for "Quick Response", which refers to the instant access to the information hidden in the code. It is a two-dimensional version of the barcode, typically made up of black and white pixel patterns. Now, it has found its way into mobile marketing with the widespread adoption of smartphones. This study explored the use of QR Codes in educational setting. The QR-coded supplemental materials were used both in modular and online distance learning since both modality use weekly home-learning plan (WHLP) being distributed to students in a regular basis. They were attached to WHLP beside the General Mathematics subject for the students to scan using their smartphones. If they don't have the scanning application in their phones, they could just encode the affixed link in WHLP through Google engines and the teacher-made brochure will automatically pop out. Upon scanning or encoding the affixed link, the learners were able to have a glance of the supplemental material. Fifteen schools, from the Department of Education, Division of Laguna, Philippines, including the home school of the author, participated. The study made use of explanatory sequential mixed method of quantitative and qualitative approaches. Findings revealed that there is a significant increase in the academic performance of Grade 11 learners in the General Mathematics when QR-coded supplemental materials were used. Both learners and teachers highly agree that QR-coded supplemental materials have various benefits in lesson preparation and understanding of key concepts and competency in General Mathematics. Themes developed are (1) Easy access is a key to understanding and learning, and (2) Less time to browse, more time to help and teach. Reflection and challenge on continuing to make ways for knowledge to be accessible was given at the end of the study.
\end{abstract}

Keywords: materials; senior high school; supplemental, QR

\section{Context and Rationale}

Instructional materials took the form of simple art paper, manipulative, natural objects in the surroundings, digital materials like video clips, PowerPoint and net sources. Teacher can be innovative in the production and use of instructional materials. There are many available ready-made materials which the Department of Educational does not only promote the use but also monitors the utilization of those available in the government sites like LRM portal. Many have explored on the benefit that can be gained from using those materials.

Getting into the concept of localization and contextualization of the curriculum, teachers are given the challenge of personalizing and doing their own instructional materials to be used in the classroom setting with the given culture of community where the school is.

This is the very reason why this action research has come into mind. The production of supplemental materials in the form of a brochure which is summarized and crafted for distance learning modality in this time of pandemic would be investigated as to its effectiveness in increasing academic performance. These supplemental materials are to be QR (Quick Response) coded and attached to the weekly home-learning plan 
of the students. Would the attachment of these QR-coded materials aid in better understanding of Math concepts? What do Math teachers of the Division of Laguna think about the use of these QR-coded supplemental materials for distance learning purposes? Those are some of the things that this paper would explore.

Selected Math teachers of the Division of Laguna were asked about the use of supplemental materials these lastly concluded school year 2020-2021. Only 10\% of them strongly agree that even without supplemental materials in Mathematics, learners are able to produce quality output using the modules available. Only $20 \%$ of them admitted that they always send supplemental materials to their learners in Mathematics. Even a lower percentage (10\%) revealed that they always produce supplemental materials and send them to their learners with the module available. There are also $10 \%$ of the selected respondents that declared that $76-100 \%$ of their learners obtained very satisfactory (or higher) performance even without supplemental materials. None of the respondents strongly agree that learners easily understand the lesson even with the absence of resource materials. Lastly, $100 \%$ of the respondents strongly agree that supplemental and resource materials are needed because not all learners are able to understand easily the available module. These things added to the motivation the researcher to conduct this study on QR-coded supplemental materials for this school year 2021-2022.

According to findings in the study made by Adipo (2015), it can be seen that the control group of schools who have not used additional instructional materials had mean and standard deviation of 52.70and 13.57, respectively, while the experimental group of schools who used additional instructional materials had a mean and standard deviation of 74.30and 8.74, respectively. The difference in performance of children in control group of schools and those in experimental group of schools was found to be statistically significant $(\mathrm{t}$ $(8)=-5.482, p=.004$, two tailed). This suggests that children who are taught mathematics using instructional materials perform better than those who are only taught mathematics using abstract mathematics symbols only. The difference in performance is due to interventions (treatment) done to the experimental group of schools.

According to Aduwa Et Al, (2005), these materials and resources include, audio tapes recorders, video tape recorders, slide projectors, still pictures, programmed instructional film strips, maps, chart, graphs and many more; offer a variety of learning experience individually or in combination to meet different teaching and learning experiences.

The "term mathematical instructional resource" is defined as any form of specific mathematical apparatus (Structured or unstructured), image, ICT game, tool, paper, or everyday material which could be utilized to provide a mathematical teaching or learning (Doreen, et. al, 2007).

Onasanya et al: (2008) noted that improvisation demands adventure, creativity, curiosity and perseverance on the part of teachers.

Ikwuas and Onwiodiket (2006) state that improvised materials involve selection and deployment of relevant instructional elements of teaching and learning processes in absence or shortage of standard teaching and learning materials, for meaningful realization of specified educational goals and objectives.

Abimbade (2004) had earlier noted that the approach of using improvised materials in mathematics classroom assist in proper introduction of new skills, develop understanding as well as show the appropriate way of doing things.

Orji (2012) in his study found out that instructional materials are not necessarily important if the learners are intelligent and the teacher has good mastery of the subject matter.

Egbu (2012) argued that involving learners in classroom activities is what matters most as it makes teaching learner centered.

In accordance with the findings in the study made by Koparan (2017), it is concluded that prospective teachers have positive views and attitudes to general teaching technologies and materials development. 
Pre-tests and post-tests were administered to the respondents before and after the use of IMs to ascertain the changes in students' performance, and Mathematics self-efficacy beliefs in terms of attitude towards Mathematics, Mathematics anxiety and motivation to do Mathematics. The three IMs in grade 7 Mathematics, High School Statistics and Method of Research were found effective in enhancing student learning.

Bolick and others (2003) pointed to a good relationship between effective teaching and use of instructional materials. He argued that even if there are some educators who found the potential of IM's in enhancing teaching and learning, most of them are behind in utilizing these materials during instruction, while others expressed doubts that these will ever provoke teaching reform.

Ogbondah (2008), stressed that the need to develop an effective instructional system is both an opportunity and a threat. It is a challenge at the same time, an opportunity to educate teachers and learning experiences based on a carefully planned learning experience.

Tahir (2002) admitted that there is general lack of IMs that match the teaching styles of teachers and learning styles of students.

\section{Research Questions}

The main focus of this action research is to find out the effectiveness of the use of QR-coded supplemental materials in attaining higher academic performance.

Specifically, it seeks to answer the following questions:

1. What is the mean level of academic performance of SHS Grade 11 learners in General Mathematics (without the aid of QR-coded supplemental materials) during the first quarter of school year 20202021 ?

2. What is the mean level of academic performance of SHS Grade 11 learners in General Mathematics (with the aid of QR-coded supplemental materials) during the first quarter of school year 2021-2022?

3. Is there a significant difference in the academic performance of Grade 11 learners with and without the use of QR-coded supplemental materials?

4. What are the benefits of using QR-coded supplemental materials to learners and math teachers?

\section{Proposed Innovation, Intervention and Strategy}

"QR" stands for "Quick Response", which refers to the instant access to the information hidden in the Code. It is a two-dimensional version of the barcode, typically made up of black and white pixel patterns. Denso Wave, a Japanese subsidiary of the Toyota supplier Denso, developed them for marking components in order to accelerate logistics processes for their automobile production. Now, it has found its way into mobile marketing with the widespread adoption of smartphones. This study would explore the use of QR Codes in educational setting. It can be used both in modular and online distance learning since both modality use weekly home-learning plan (WHLP) being distributed to students in a regular basis. It will be attached to WHLP beside the General Mathematics subject for the students to scan using their smartphones. If they don't have the scanning application in their phones, they can just encode the affixed link in WHLP through Google engines and the teacher-made brochure will automatically pop out. The sample attachment of QR-code with its corresponding https link is shown here: 


\begin{tabular}{|c|c|c|c|c|}
\hline $9: 50-10: 40$ & General Mathematics & $\begin{array}{l}\text { SOLVING LOGARITHMIC } \\
\text { EQUATIONS AND } \\
\text { INEQUALITIES }\end{array}$ & $\begin{array}{l}\text { WHAT I HAVE LEARNED } \\
\text { * Sentence completion, } 10 \text { items (p. 639) } \\
\text { * Copy and answer } \\
\text { WHAT I CAN DO } \\
\text { * Journal writing. (p. } 640 \text { ) } \\
\square \text { Upper left part, surname, first name, m.i., section } \\
\square \text { Don't attach any paper (even small pcs.) in front. } \\
\square \text { Accomplish the } 2 \text { activities in just } 1 \text { long bond paper }\end{array}$ & MDL \\
\hline \multirow{4}{*}{$10: 40-11: 30$} & \multirow{3}{*}{ Earth and Life Science } & $\begin{array}{l}\text { Using hazard maps, identify areas } \\
\text { prone to hazards brought about by } \\
\text { tropical cyclones, monsoons, floods, } \\
\text { or ipo-ipo. }\end{array}$ & $\begin{array}{l}\text { Week } 8 \text { (Pages 296-306) Read and answer the following activities: } \\
\text { (Use long bond paper. You can use the back of each long bond paper in answering.) } \\
\text { 1. Assessment (Copy and Answer) (pp. 304-305) }\end{array}$ & \multirow{3}{*}{ MDL } \\
\hline & & $\begin{array}{l}\text { Describe how coastal processes result } \\
\text { in coastal erosion, submersion, and } \\
\text { saltwater intrusion. }\end{array}$ & $\begin{array}{l}\text { Week } 8 \text { (Pages } 308-325) \text { Read and answer the following activities: } \\
\text { (Use long bond paper. You can use the back of each long bond paper in answering.) } \\
\text { 1. Activity 4. Poster Making. (p. 319) } \\
\text { 2. Assessment (ANSWER ONLY) (pp. 321-322) }\end{array}$ & \\
\hline & & $\begin{array}{l}\text { Cite ways to prevent or mitigate the } \\
\text { impact of land development, waste } \\
\text { disposal and construction of } \\
\text { structures on control coastal } \\
\text { processes. }\end{array}$ & $\begin{array}{l}\text { Week } 8 \text { (Pages 327-347) Read and answer the following activities: } \\
\text { (Use long bond paper). You can use the back of each long bond paper in answering.) } \\
\text { 1. What's More. Activity 5: Making an action plan. (Copy the table then answer) } \\
\text { (Please do not copy the example and formulate your own action plan. One action plan } \\
\text { is enough, do not fill-in the second rows.) (No need to answer the guide questions) (p. } \\
\text { 339) } \\
\text { 2. Assessment (ANSWER ONLY) (pp. 343-345) }\end{array}$ & \\
\hline & & & $\begin{array}{l}\text { (1st) Read first your Module Title: } 21 \text { st Century Literature from the Philippines } \\
\text { and the World Elements of a Short Storv }\end{array}$ & \\
\hline
\end{tabular}

Upon scanning or encoding the affixed link, the learners will be able to have a glance of the supplemental material. This supplemental material follows the learners' pace for it basically contains motivation (Let's Reconnect), review of past lesson or competency exercise (Think about This), abridged lecture (What Must We Know), further examples (Getting into It), application (Try This), enhancement (Digging Deeper), and the closure part which aids in the reflection and life application. The competency embedded in the supplemental material follows the Most Essential Learning Competency (MELC) by the Department of Education. It has been distributed to the learners of Talangan Integrated National High School during the pre-pandemic and even during the pandemic, but not yet in QR-coded format, that is, it has not yet been fully utilized in a large scale. Its special feature of being abridged can assist learners in reading it in a glance and remember the most important concepts that they need to remember for each of the specific topics in General Mathematics. The sample content of the QR Code when scanned is presented on the next page.

\section{Action Research Methods}

The study will make use of an exploratory-sequential mixed method, in which both quantitative and qualitative design will be used. Montgomery (1997) defines this combination as a process of obtaining numerical data followed by interview, either oral or written, and then comparing the numerical data with the responses on interviews, thereby establishing the validity of the findings.

\subsection{Participants and/or other Sources of Data and Information}

With more than 50 SHS institutions in the province of Laguna (Source: https://www.listph.com/2015/10/list-of-public-senior-high-schools-deped-laguna. html), selected schools will be invited to participate through a letter, with the assistance of the Department of Education Division Office of Laguna. Using the concept of convenience sampling, the number of participating SHS was based on the response of the invited schools. 


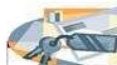

Try this!

Solve for $x$

1. $\log _{2} x=2 \log _{2} 4-\log _{2} 2$

2. $2 \log _{3} x=\log _{3} 2+\log _{3}(4-x)$

3. $\log _{2} x+\log _{2}(x-3)=3$

4. $(3 a)^{x+4}=\left(27 a^{3}\right)^{x+6}$

5. $\log _{3} x+\log _{3}(x-2)=1$

6. $(2 x-1)^{5}=-32$

Digging deeper!

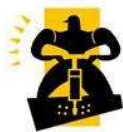

Solve for $\mathrm{x}$.

1. $\log _{4}(x+1)+\log _{4} 5=2$

2. $\log _{3}\left(x^{2}-22\right)=3$

3. $\log _{4} x+\log _{4}(x+2)=1 / 2 \log _{4} 9$

4. $\log _{4}(x+6)+\log _{4} x=2$

5. $\log _{2}(x-3)+\log _{2} 3=3$

6. $\log _{4}\left(x^{2}-17\right)=3$

\section{Closure}

Solving life's problems does not always require experience, for in facing those trials, we already gain experience. What we actually need is the wise advise of someone with supremely higher insight than us-God.

Elymar A. Pascual

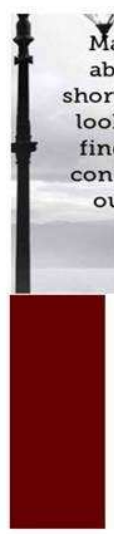

Many people know so little about what is beyond their hort range of experience. They look within themselves - and find nothing! Therefore they conclude that there is nothing outside themselves either.

\section{- Helen Keller}

ACKNOWLEDGEMENT

Some parts of this learner's material are original of the

author, and other parts,

especially the Getting into it!

portion was adopted from

copyright 2016.

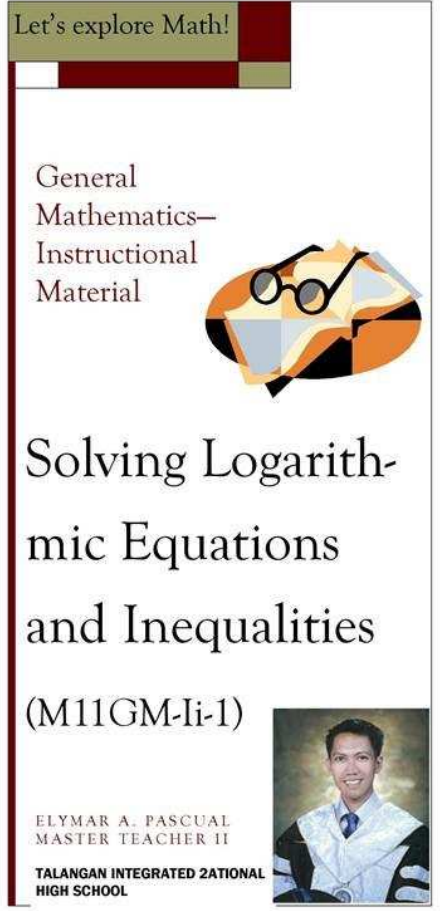

\section{General Mathematics
The Human Calculator, aka
the 3-7-13-37 Trick} Let's reconnec

This trick will make it appear that you are the world's fastest human calculator. To make it realistic. hand friend the iOS calcillor pencin for yourself

fiend pick anv 2 digit number ( 82 , for example) 2. Tell your friend to multiply this number by 3 and hit (

3. Then multiply that result by 7 and hit enter/equal $(246 \times 7$ $=1,722$ )

4. Then multiply that result by 13 and hit enter/equal $(1722 \times$ $13=22,386$ )

5 . Then multiply that result by 37 and hit enter/equal $(22386 x$ $7=828,282)$

6. While you friend is typing numbers furiously on your iPhone, you can write down the first number three times and find the answer in a matter of seconds. $(82-82-82=828282=$ Source: www.engadget.com

(2) $\rightarrow$ Think about this!

Let's have a review. Answer the following:

1.) What is the equivalent of the logarithm of a number?

2.) What is a logarithm?

3.) What is a logarithmic function?

What Must We Know

Logarithms

The logarithm of $x$ to the base $b$ is defined by

$y=\log _{b} x$ if and only if $x=b^{y} \quad(x>0)$

Ex. $\log _{3} 81=4 ; \quad\left(3^{4}=81\right)$

$\log _{7} 1=0 ; \quad\left(7^{0}=1\right)$

$\log _{1 / 3} 9=-2 ; \quad\left(\left(\frac{1}{3}\right)^{-2}=81\right)$

$\log _{5} 5=1$ : $\left(5^{1}=5\right)$

Logarithmic Function The logarithmic function of $x$ to the base $b$ is defined by

Properties:

$f(x)=\log _{b} x \quad(b>0, b \neq 1)$

1. Domain: $(0, \infty)$

2. Range: $(-\infty, \infty)$

3. $x$-intercept: $(1,0)$

. Conthuous on $(0, \infty)$

5. Increasing on $(0, \infty)$ if $b>1$
Decreasing on $(0, \infty)$ if $b<1$

Graphs of Logarithmic Functions

Ex. $f(x)=\log _{3} x \quad f(x)=\log _{1 / 3} x$

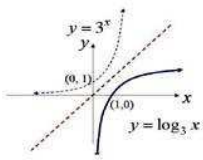

prepared by EAPascual

Getting into it

Examples

Ex. Solve each equation

a. $\log _{2} x=5$

$x=2^{5}=32$

b. $\log _{27} 3=x$

$3=27^{x}$
$3=3^{3 x}$

$3=3^{3 x}$
$1=3 x \quad\left(a^{m}=a^{n} \Rightarrow m=n\right)$

$\frac{1}{3}=x$

Example

Use the laws of logarithms to simplify the

expression: $\log _{5} \frac{25 x^{7} y}{\sqrt{z}}$

$=\log _{5} 25+\log _{5} x^{7}+\log _{5} y-\log _{5} z^{1 / 2}$

$=2+7 \log _{5} x+\log _{5} y-\frac{1}{2} \log _{5} z$

$e^{x}$ and $\ln x$

$e^{\ln x}=x \quad(x>0)$

$\ln e^{x}=x \quad$ (for any real number $x$ )

Ex. Solve $\frac{1}{3} e^{2 x+1}=10$

$2 x+1=\ln (30) \quad$ Apply In to both sides.

$x=\frac{\ln (30)-1}{2} \approx 1.2$ 


\subsection{Data Gathering Methods}

Both quantitative and qualitative data will be used in answering questions posted at the beginning of the study. Google Form will be used to solicit responses. For the quantitative data, the general average of learners in General Mathematics in school years 2020-2021 and 2021-2022 will be gathered, recorded, analyzed and interpreted. For the qualitative data, response to survey questions on effectiveness of teachermade brochure were sorted, analyzed and interpreted.

\section{Discussion of Results and Reflection}

\subsection{Academic Performance of Grade 11 SHS Learners without the Aid of QR-Coded Supplemental Materials}

Table 1. Academic performance in General Mathematics for first quarter of school year 2020-2021

\begin{tabular}{|c|c|c|c|c|}
\hline Academic Standing & Frequency & Percentage & Mean & SD \\
\hline Outstanding (90-100) & 179 & 10.08 & 71.62 & 76.42 \\
\hline Very Satisfactory (85-89) & 277 & 15.60 & 81.86 & 1.41 \\
\hline Satisfactory (80-84) & 478 & 26.91 & 86.60 & 1.44 \\
\hline Fairly Satisfactory (75-79) & 549 & 30.91 & 91.98 & 1.49 \\
\hline Failed (below 75) & 293 & 16.50 & $\mathbf{8 0 . 2 5}$ & 1.58 \\
\hline Overall & $\mathbf{1 , 7 7 6}$ & $\mathbf{1 0 0}$ & $\mathbf{6 . 3 7}$ \\
\hline
\end{tabular}

The table above shows the academic performance of Grade 11 learners during the first quarter of school year 2020-2021, when the QR-coded supplemental materials were not yet distributed to learners. It can be seen that out of 1, 776 learners from fifteen Senior High Schools in the Division of Laguna, the greatest percentage of learners' academic performance can be seen under the category fairly satisfactory, which comprises grades from 75 to 79 . The least percentage on the other hand goes to the learners with academic performance which is outstanding (grades with 90 to 100). With regards to that range which is 90 and to 100 , this is the decision of the Department of Education to stretch the range because of the fact that adjustment has to be made during this time of pandemic in which both mental and psychosocial state of learners are affected. Those who attain 90 and above are already considered under Outstanding to acknowledge their effort and encourage them to keep going despite pandemic. The overall mean of the 1, 776 learners coming from 15 SHS is 80.25 , interpreted as satisfactory, based from the range of scores. The standard deviations which are all greater than 1 signify heterogeneity of learners coming from different schools with different strands and tracks.

5.2. Academic Performance of Grade 11 SHS Learners with the Aid of QR-Coded Supplemental Materials

Table 2. Academic performance in General Mathematics for first quarter of school year 2021-2022

\begin{tabular}{|c|c|c|c|c|}
\hline Academic Standing & Frequency & Percentage & Mean & 72.03 \\
\hline Outstanding (90-100) & 225 & 8.27 & 76.87 & 2.58 \\
\hline Very Satisfactory (85-89) & 318 & 11.69 & 81.51 & 0.25 \\
\hline Satisfactory (80-84) & 1399 & 51.41 & 86.54 & 1.35 \\
\hline Fairly Satisfactory (75-79) & 544 & 19.99 & 92.37 & 1.86 \\
\hline Failed (below 75) & 235 & 8.64 & $\mathbf{8 1 . 2 5}$ & \\
\hline Overall & $\mathbf{2 , 7 2 1}$ & $\mathbf{1 0 0}$ & $\mathbf{5 . 1 5}$ \\
\hline
\end{tabular}

The table above shows the academic performance of Grade 11 learners during the first quarter of school year 2021-2022, when the QR-coded supplemental materials already being distributed to learners. There is considerably high increase of enrolment from last school year's 1, 776 to this school year's 2, 721, 
which is equivalent to $53.21 \%$ increase. This can be attributed to the fact that many grade 10 completers who would be clients of private SHS decided to enroll in public SHS, and also the transferees from the private institutions. Another factor that might have caused the increase are the coming of returning students who stopped studying and decided to continue this school year, plus the completers of Alternative Learning System of the government. It can be seen that out of 2, 721 learners from fifteen Senior High Schools in the Division of Laguna, the greatest percentage of learners' academic performance can be seen under the category satisfactory, which comprises grades from 80 to 84 . The change of greatest percentage from fairly satisfactory of last school year to satisfactory this school year is noticeable. The least percentage on the other hand goes to the learners with academic performance which is outstanding (grades with 90 to 100). The overall mean of the 2, 721 learners coming from 15 SHS is 81.25 , interpreted as satisfactory, based from the range of scores. The increased from last school year to this school year's overall mean is once again noticeable. The standard deviation of the category group satisfactory is a good sign that these learners are having commonality or their grades are near each other. For other standard deviations which are greater than 1 signify heterogeneity of learners coming from different schools with different strands and tracks.

\subsection{Effect of the Use of QR-Coded Supplemental Materials}

Table 3. T-test of independent samples for difference between academic performances

\begin{tabular}{|c|c|c|c|c|c|c|}
\hline Incident & Mean & SD & t-computed & t-critical & P-value & Decision \\
\hline $\begin{array}{c}\text { Without the } \\
\text { aid of QR- } \\
\begin{array}{c}\text { Coded Supp. } \\
\text { Mat. }\end{array}\end{array}$ & 80.25 & 6.37 & & & & \\
\cline { 1 - 2 } $\begin{array}{c}\text { With the Aid } \\
\text { of QR-Coded } \\
\text { Supp. Mat. }\end{array}$ & 81.25 & 5.15 & -5.80 & 1.96 & & \\
\hline
\end{tabular}

The table above shows the t-test result for independent samples, highlighting the significant difference of means between the two groups. The difference of the mean performance of learners in General Mathematics last first quarter of school year 2020-2021 (80.25)and the mean performance of learners this school year 2021-2022 (81.25) is equal to 1. The lower standard deviation with the use of QR-coded supplemental materials indicates a less varied academic performance, and it is a good report. The increase of 1 unit in the academic performance is seen as significant because the absolute value of the t-computed (5.80) is greater than the t-critical value. This is supported by the P-value $(0.00)$ which is less than the alpha value (0.05). With 95\% level of confidence, it can be said that the use of QR-coded supplemental materials significantly affect the increase in academic performance.

The findings that result out of this study have similar result with the study made by Adipo (2015). Additional instructional materials can significantly increase the performance of learners because the understanding or comprehension of learners is heightened. Supplemental materials enhance learners' skill and provides them with clearer view of the topic being taught by the teacher.

\subsection{Benefits of QR-Coded Supplemental Materials to Learners}

Table 4. Benefits of QR-coded supplemental materials to learners

\begin{tabular}{|c|c|c|c|}
\hline The QR-coded supplemental materials benefit the learners through... & Mean & SD & Interpretation \\
\hline 1. facility in reading and learning the needed competency through abridged pre & 4.11 & 0.90 & Highly Agree \\
\hline 2. low data requirement compared to endless browsing of supplemental materials. & 3.97 & 1.07 & Highly Agree \\
\hline
\end{tabular}




\begin{tabular}{|c|c|c|c|}
\hline 3. aid in attaining better output and increased academic performance. & 4.22 & 0.87 & $\begin{array}{l}\text { Very Highly } \\
\text { Agree }\end{array}$ \\
\hline 4. provision of quick look at important terms, formulas and sample solved problems. & 4.40 & 0.84 & $\begin{array}{l}\text { Very Highly } \\
\text { Agree }\end{array}$ \\
\hline 5. challenging learners' thinking through the activities provided. & 4.14 & 0.92 & Highly Agree \\
\hline 6. gaining additional practice through the enhancement exercises. & 4.22 & 0.76 & $\begin{array}{l}\text { Very Highly } \\
\text { Agree }\end{array}$ \\
\hline $\begin{array}{l}\text { 7. facility in keeping materials in data storage because the materials is downloadable or can be } \\
\text { screenshot with minimum data requirement. }\end{array}$ & 4.22 & 0.93 & $\begin{array}{l}\text { Very Highly } \\
\text { Agree }\end{array}$ \\
\hline 8. leading learners in maximizing the use of their gadget and in being globally competitive. & 4.08 & 0.94 & Highly Agree \\
\hline 9. addition of motivation because of the priming activity presented in the materials. & 4.23 & 0.95 & $\begin{array}{l}\text { Very Highly } \\
\text { Agree }\end{array}$ \\
\hline 10. guidance in learning because of the proper pacing of contents in the materials. & 4.15 & 0.99 & Highly Agree \\
\hline Average & 4.17 & 0.92 & Highly Agree \\
\hline
\end{tabular}

Legend: $\quad 4.21-5.00$ - Very Highly Agree

$3.41-4.20$ - Highly Agree

$2.61-3.40-$ Agree

$1.81-2.60$ - Somehow Agree

$1.00-1.80$ - Disagree

The table above shows the evaluation of the teachers and learners to the QR-coded supplemental materials, specifically on the benefits it creates to the learners. The 65 learners and teachers agree that QRcoded materials facilitates in reading in learning, which a mean value of 4.11, standard deviation of 0.90 , and an interpretation of highly agree. The low data requirement of the QR-coded materials was agreed by the respondents at a mean value of 3.97, SD of 1.07, interpreted as highly agree. Aid in attaining better output gained a mean value of 4.22 , SD of 0.87 , interpreted as very highly agree. Provision of quick look at important Math concepts gained a mean value of 4.40 , SD of 0.84 , interpreted as very highly agree. Challenging learners' critical thinking gained a mean value of 4.14, SD of 0.92, interpreted as highly agree. Gaining additional practice landed at a mean value of 4.22 , SD of 0.76 , interpreted as very highly agree. Facility in keeping materials in data storage gained a mean value of 4.22 , SD of 0.93 , interpreted as very highly agree. Leading learners in maximizing the use of their gadget gained a mean value of 4.08, SD of 0.94, interpreted as very highly agree. Addition of motivation because of priming activity gained a mean value of 4.23 , SD of 0.95 , interpreted as very highly agree. Guidance in learning because of the proper pacing of the content gained mean value of 4.15 , SD of 0.99 , interpreted as highly agree. The overall mean value of perception of the respondents with regards to the benefits of QR-coded materials to the learners is 4.17, SD of 0.92, interpreted as highly agree. The standard deviation of mostly less than 1 implies harmony in the perception of the respondents.

\subsection{Benefits of QR-Coded Supplemental Materials to Math Teachers}

Table 5. Benefits of QR-coded supplemental materials to teachers

\begin{tabular}{|c|c|c|c|}
\hline The QR-coded supplemental materials benefit the teachers through... & Mean & SD & Interpretation \\
\hline 1. reduction of stress to teachers in looking for supplemental materials. & 4.03 & 0.95 & Highly Agree \\
\hline $\begin{array}{l}\text { 2. addition of fulfillment in teaching when learners acquire the competency needed through the } \\
\text { QR-coded materials. }\end{array}$ & 4.22 & 0.82 & $\begin{array}{l}\text { Very Highly } \\
\text { Agree }\end{array}$ \\
\hline $\begin{array}{l}\text { 3. assistance to teachers in selecting, developing, organizing and using appropriate teaching and } \\
\text { learning resources using ICT. }\end{array}$ & 4.20 & 0.94 & Highly Agree \\
\hline $\begin{array}{l}\text { 4. facility in teaching through the abridged materials that focuses in the target competency } \\
\text { needed per CG Code or per MELC. }\end{array}$ & 4.09 & 0.95 & Highly Agree \\
\hline 5. reduction of time in looking for additional examples of solving problems in Gen Math topics. & 4.23 & 0.84 & $\begin{array}{l}\text { Very Highly } \\
\text { Agree }\end{array}$ \\
\hline $\begin{array}{l}\text { 6. assistance to teachers in providing learners with additional activity especially those who ar } \\
\text { lagging behind. }\end{array}$ & 4.28 & 0.90 & $\begin{array}{l}\text { Very Highly } \\
\text { Agree }\end{array}$ \\
\hline
\end{tabular}




\begin{tabular}{|c|c|c|c|}
\hline $\begin{array}{l}\text { 7. assistance to teachers in looking for supplemental materials because the materials are printable } \\
\text { and shareable. }\end{array}$ & 4.28 & 0.82 & $\begin{array}{l}\text { Very Highly } \\
\text { Agree }\end{array}$ \\
\hline 8. facility in integrating values to learners through the reflection presented in the materials. & 4.23 & 0.93 & $\begin{array}{l}\text { Very Highly } \\
\text { Agree }\end{array}$ \\
\hline $\begin{array}{l}\text { 9. provision of secure storage of knowledge because it has embedded url, especially for those } \\
\text { who have no QR scanner. }\end{array}$ & 4.18 & 0.86 & Highly Agree \\
\hline $\begin{array}{l}\text { 10. low cost of production for modular distance learning because every material just needs one } \\
\text { bond paper. }\end{array}$ & 4.14 & 0.98 & Highly Agree \\
\hline Average & 4.19 & 0.90 & Highly Agree \\
\hline
\end{tabular}

Legend: $4.21-5.00$ - Very Highly Agree

$3.41-4.20$ - Highly Agree

$2.61-3.40$ - Agree

$1.81-2.60$ - Somehow Agree

$1.00-1.80$ - Disagree

The table above shows the evaluation of the teachers and learners to the QR-coded supplemental materials, specifically on the benefits it creates to the teachers. The 65 learners and teachers agree that QRcoded materials facilitates in reading in learning, which a mean value of 4.11, standard deviation of 0.90 , and an interpretation of highly agree. The low data requirement of the QR-coded materials was agreed by the respondents at a mean value of 3.97, SD of 1.07, interpreted as highly agree. Aid in attaining better output gained a mean value of 4.22 , SD of 0.87 , interpreted as very highly agree. Provision of quick look at important Math concepts gained a mean value of 4.40, SD of 0.84 , interpreted as very highly agree. Challenging learners' critical thinking gained a mean value of 4.14, SD of 0.92, interpreted as highly agree. Gaining additional practice landed at a mean value of 4.22 , SD of 0.76 , interpreted as very highly agree. Facility in keeping materials in data storage gained a mean value of 4.22 , SD of 0.93 , interpreted as very highly agree. Leading learners in maximizing the use of their gadget gained a mean value of 4.08, SD of 0.94, interpreted as very highly agree. Addition of motivation because of priming activity gained a mean value of 4.23 , SD of 0.95 , interpreted as very highly agree. Guidance in learning because of the proper pacing of the content gained mean value of 4.15 , SD of 0.99 , interpreted as highly agree. The overall mean value of perception of the respondents with regards to the benefits of QR-coded materials to the learners is 4.17, SD of 0.92, interpreted as highly agree. The standard deviation of mostly less than 1 implies harmony in the perception of the respondents.

\subsection{Qualitative Feedback to the Benefits of QR-Coded Supplemental Materials}

Table 6. Sample responses on the benefits of QR-coded materials for learners and teachers

\begin{tabular}{|l|l|}
\hline No. & \multicolumn{1}{|c|}{ Selected Responses } \\
\hline 1 & Very helpful \\
\hline 2 & I think the shorter time you spend because of QR Code and this one are the benefits of it. \\
\hline 3 & $\begin{array}{l}\text { The benefits of the QR codes supplementary material to learners and teachers are to understand the lesson of the Modular } \\
\text { learning and etc. And what you do in the module learning }\end{array}$ \\
\hline 4 & $\begin{array}{l}\text { Very helpful especially to my students who are really busy in their work. Most of my students are already working so they have } \\
\text { limited time in studying; the topics on QR-coded supplemental were easily understood by my students. }\end{array}$ \\
\hline 5 & Can enable students to access more resources related to the subject. \\
\hline 6 & It's easy to give students web address \\
\hline 7 & The QR code helps to facilitate student engagement and ensure that they have access to the right material. \\
\hline 8 & It makes the modular based learning easier and more convenient \\
\hline 9 & The QR code promotes student engagement and ensures that they have access to the appropriate materials. \\
\hline 10 & The qr coded supplemental materials is very organize, and informative. I suggest that the supplemental should have answer keys. \\
\hline 11 & It helps us gaining some practice \\
\hline 12 & It helps us understand the topic or the lesson more efficiently and it guide us to do the task or activity properly. \\
\hline 13 & It helps to facilitate teacher and student engagement and ensure that they have access to the right material. \\
\hline 14 & Helps us teachers to comply with some mandated orders. \\
\hline
\end{tabular}




\begin{tabular}{|c|c|}
\hline 15 & It will save time for them (learners and teachers). \\
\hline 16 & It helps us easier to understand the lessons. \\
\hline 17 & It can access more resources and things for them to enable new things that might they learned from any relating subjects. \\
\hline 18 & Get extra information in presentation and Course content \\
\hline 19 & $\begin{array}{l}\text { If for the teacher they will no longer have difficulty in doing modules. And for other students who can't afford to buy a gadget or } \\
\text { don't have budget to buy load in cellphone, it's hard for they to keeping up with it. }\end{array}$ \\
\hline 20 & $\begin{array}{l}\text { the reason why then are more useful than a standard barcode is that they can store and digitally present much more data } \\
\text { including URL links geo coordinates and text the other key feature of QR-codes is that instead of requiring a chunky hand held } \\
\text { scanner to scan them many modern cellphones can scan them }\end{array}$ \\
\hline 21 & QR-coded supplemental is useful because you don't need to ask your teacher cause sometimes they are busy. \\
\hline 22 & I think the benefits of the QR-coded are probably to help us learners to easily understand the topic in gen math. \\
\hline 23 & $\begin{array}{l}\text { It is a user friendly and easy to access provided that you have internet connection. It is very timely for this extra-ordinary time. } \\
\text { Thank you for this opportunity. }\end{array}$ \\
\hline 24 & $\begin{array}{l}\text { The QR code helps to facilitate student engagement and ensure that they have access to the right material. With the huge number } \\
\text { of websites that are not child friendly, use of QR codes prevents accidents where students access inappropriate sites. }\end{array}$ \\
\hline 25 & It costs less. \\
\hline 26 & $\begin{array}{l}\text { QR Codes are a perfect example of how teachers can positively integrate technology in their classrooms because they're so easy } \\
\text { and flexible to use. Many children already have smartphones, so they can use their smartphones (and also tablets in class) and } \\
\text { scan the QR Codes to do things like save homework, find quiz answers, and access links easier. Plus, it also saves on loads of } \\
\text { paperwork }\end{array}$ \\
\hline 27 & easy to access \\
\hline 28 & It gives less stress for the students as it provides clear instructions about a certain activity that we are tasked to do. \\
\hline 29 & It is unique and stress free in availing the learning materials for teachers and students in the new normal. \\
\hline 30 & $\begin{array}{l}\text { QR codes can provide more information about the product or service without a sweat and the information quickly goes to the } \\
\text { user's device. }\end{array}$ \\
\hline 31 & Less printing for teachers and students can easily access if they have internet and cellphone. \\
\hline 32 & $\begin{array}{l}\text { Dr. Pascual's QR code really helps me as math teacher it is appropriate for teaching materials that students benefited to QR code } \\
\text { a lot. }\end{array}$ \\
\hline 33 & $\begin{array}{l}\text { Verify comprise and compact, for teachers, easy to explain to the students. For students, easy for them to understand the lesson } \\
\text { in every topic. }\end{array}$ \\
\hline 34 & $\begin{array}{l}\text { QR-coded supplemental materials helped my students a lot in understanding our topics in General Mathematics. QR codes } \\
\text { provide convenience in accessing the supplemental materials. In addition to this, the simplified presentation of topics through } \\
\text { supplemental helps my students overcome their Math anxiety as they realized that they can understand the topic by giving just } \\
\text { enough information and examples as compared to modules loaded with too much examples and info. }\end{array}$ \\
\hline 35 & $\begin{array}{l}\text { Lessen time consumption in delivering or transferring lessons or any transactions, and is therefore lessen also the physical } \\
\text { contact. }\end{array}$ \\
\hline
\end{tabular}

The table above shows selected, unique responses from the survey conducted, asking for qualitative response from the question, "What do you think are some other benefits of the QR-coded supplemental to learners and teachers? The fourteen participant teachers and 52 learners coming from different schools (making a total of 66 respondents) were able to answer the survey. From the responses, the 2D-Word Cloud formed and the table of frequently appearing words are as follows:

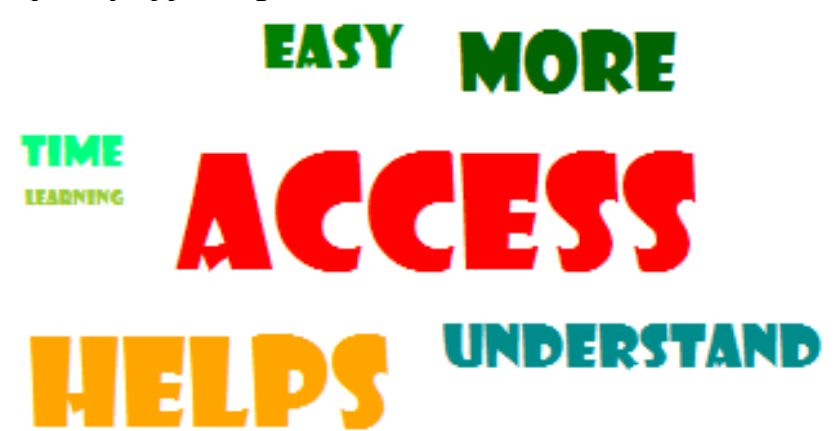

Fig. 1. 2D-word cloud of frequently appearing words in benefits of QR-coded supplemental materials 
Table 7. Table of frequently appearing words in benefits of QR-coded supplemental materials

\begin{tabular}{|c|c|c|}
\hline No. & Word & Frequency \\
\hline 1 & access & 11 \\
\hline 2 & helps & 9 \\
\hline 3 & more & 7 \\
\hline 4 & understand & 6 \\
\hline 5 & easy & 6 \\
\hline 6 & time & 5 \\
\hline 7 & learning & 4 \\
\hline
\end{tabular}

Analyzing the frequently appearing words against the raw document response, the resulting first theme is thus formulated:

Theme1 (Benefit for learners):

Easy access is a key to understanding and learning.

The QR-coded supplemental device took the attention of the learners because of the way it is accessed. Aside from the facility in accessing the document, the associated URL gave them a quick way of having an abridged lesson of the topic that they need to study. The content of the QR-coded supplemental material provided them additional understanding and learning, making clear what can be read from the module provided to them by the Department of Education.

The second theme that is formulated out of the 2D-Word Cloud and its associated table of frequency appearing words is written below:

Theme 2 (Benefit for teachers):

Less time to browse, more time to help and teach.

With all the tasks of teachers in preparing lesson exemplar, checking outputs, and administering assessment either online or through modular approach, the QR-coded supplemental materials provided them facility in looking for supplemental materials. This deducted time of browsing for enhancement material is thus allotted to more time in helping learners understanding the topic, probably by answering their concerns through social media or other means of communication wherein learners are inquiring of clarification of the lesson presented in the module. The QR-coded material which aids in learners' understanding of the topic, thus, takes its role of explaining difficult concepts. The teacher, then, can do other tasks like checking of output, paper preparations, and other tasks related to their duty as a teacher.

Through the survey provided to the teachers and learners, the following benefits were arrived at:

The QR-coded supplemental materials benefit the learners through...

1. facility in reading and learning - The QR-coded supplemental materials

2. low data requirement

3. aid in attaining better output

4. provision for quick look at knowledge

5. challenge to learner's critical thinking

6. for gaining additional practice

7. facility in keeping materials in data storage

8. leads learners in maximizing the use of gadget

9. motivation through priming activities

10. guidance in learning 
Also, the QR-coded supplemental materials benefit the teachers through...

1. reduction of stress

2. addition of teaching fulfillment

3. assistance in selecting and developing learning resources

4. facility in teaching

5. reduction of time in looking for math problems

6 . assistance in providing additional activity

7. assistance in looking for printable and shareable materials

8. facility in integrating values

9. provision of secure storage of knowledge

10. low cost of production

\subsection{Reflection}

This pandemic calls for the innovative ideas of educators to effectively deliver quality education to the $21^{\text {st }}$ century learners. It can be seen in this study that learners indeed are fun of exploring things in a click of their fingers and would want instant access to information, not just in current news, politics, showbusiness, and daily living, but in the education aspect as well. While others may have the patience of reading bulky materials, novels and lengthy discourses, we will agree that the youth of today would want to speed-up many things, including the acquisition of knowledge. The author realized through this study that educators has a great challenge of adopting into the "seemingly weakness" of the present generation. The term seemingly weakness signify the possible generation gap of the teachers and the youth of today, making the former misunderstood the latter in their behavior, upbringing and whims. The prevailing truth is that every generation has their characteristics and style of learning, in that, educators, should initiate reaching out to them. This is the very reason why this study was conducted - reaching out to the needs and style of learning in this time of pandemic. Educators should never stop of making ways for knowledge to be accessible given the present scenario and considering the ways in which the youth access information in the platforms that they know and capable of. But not only that. The goal of education is to make the youth of today realize that they are responsible for their decisions and actions toward seeking knowledge. They need to learn to look towards their goal, while at the same time taking advantage of every opportunity to learn and having that desire of not wanting to miss the joy of acquiring knowledge and skill.

\section{Acknowledgement}

The author wishes to acknowledge the following SHS Math teachers and institutions who have given their utmost participation in gearing towards the success of this study:

- Jayson M. Pedron - Gov. Felicisimo T. San Luis National Agro-Industrial Integrated High School

- Daisy Burgos De Ocampo - B. N. Calara Intergrated National High School

- Marlon Lindio Coronia - Famy National Integrated High School

- May Cabantog - Pagsanjan Senior High School

- Vergel V. Ballesteros - Pila Senior High School

- Leah Pascual Mendiola - Pakil Senior High School

- Laarni B. Rebong - San Francisco Integrated National High School

- Nelia D. Amara - Nicolas L. Galvez Memorial Integrated National High School

- Jason P. Vista - Gov. Felicisimo T. San Luis Integrated Senior High School

- Ira Rea-Cabatuando - Alaminos Integrated National High School

- Lovely Mae G. Ortillano - Masapang Integrated National High School

- Marry Anne Alcantara-Valenzuela - Banca-Banca Integrated National High School 
- Rina N. Español - Magdalena Integrated National High School

- Virginia M. Nerpiol - Lumban Senior High School

- The author's institution - Talangan Integrated National High School

\section{References}

Abimbade, C.T. (2004). Effective primary school science teaching, meaning, scope and strategies in T.O oyetunde, Y.A, Mallam and G.A and Zagi (ed). The practice. of teaching, perspective and strategiesPP 176-186. Jos LECAPE publishers.

Adipo, J. A. (2015). IMPACT OF INSTRUCTIONAL MATERIALS ON ACADEMIC ACHIEVEMENT IN MATHEMATICS IN PUBLIC PRIMARY SCHOOLS IN SIAYA COUNTY, KENYA. A Research Project Submitted to the University of Nairobi in Partial Fulfilment of the Requirements for the Masters of Education Degree (M.Ed) in Measurement and Evaluation.

Aduwa-Ogiegbaen S.O et al. (2005). Instructional Communication and Technology in higher education badan. Stirling Hordon Publishers(Nig)Ltd.

Bolick, C. Berson, M. Couts, C. \& Heinecke, W. (2003). Technology applications in social studies teacher education: A survey of social studies methods faculty, contemporary issues in technology and teacher education; 3(3).

Doreen, D. Et Al (2007). Using resources to Support Mathematical thinking in Primary and Early Years, Learning Matters Ltd.

Egbu, N. C. (2012). Approach To Teaching Methodologies. Abakaliki: Bolton Publishers Ltd

Ikwuas, O.A, Onwidiket, Y. (2006). Mathematics Phobia; Diagnosis and Prescription. First Annual Lecture: National Mathematics Centre, Abuja.

Koparan, T. (2017). Analysis of Teaching Materials Developed by Prospective Mathematics Teachers and Their Views on Materials Development. Mathematics Education Department, Ereğli Faculty of Education, Bülent Ecevit University, Zonguldak, Turkey

Montgomery, D.C (1997). Design And Analysis of Experiments (4th Edition 0 New York :John Wiley \&Sons.

Oriji, E. N (2012).Need For Using Instructional Materials In Junior Secondary Schools In Afikpo North. Unpublished NCE Project Ebonyi State College Of Education IKWO.

Ogbondah, L. (2008). An Appraisal of Instructional Materials Used to Educate Migrant Fishermen's Children in River's State, Nigeria. International Journal of Scientific Research in Education. Vol. 1(1), 13-25.

Onasanya, et Al (2008).Education Performance and Assessment of Teachers' competence In Instructional Media Technologies In Junior Secondary Schools In Kwara Estate. In: Education Reforms In Nigeria. Past, Present and Future. Lawal.A.R (EDS) Stirling. Horden Publishers Ltd, Lagos, pp 259-272.

Prado, et. al. (2015). Effectiveness of Instructional Materials in High School Mathematics, Statistics and Methods of Research on Students' Performance. Professional Education Department. Central Mindanao University. The Philippine Journal for Graduate Education. Volume 1, Issue 1, February 2015

Tahir, G. (2002). Educating Disadvantaged Groups: The Case of Nomads in Nigeria, Journal of the World Council for Curriculum and Instruction (WCCI), Nigeria Chapter, 3(2), 135-147 